\title{
A taxonomic review of Japanese Asteia (Diptera: Acalyptrata: Asteiidae)
}

\author{
Masamtro SUEYOSHI
}

Insect Ecology Laboratory, Forestry and Forest Products Research Institute, 1 Matunosato, Tsukuba, Ibaraki, 305-8687 Japan (Domestic Research Fellow, Japan Society for the Promotion of Science); e-mail: msuey@ffpri.affrc.go.jp

Key words. Diptera, Asteiidae, Asteia, taxonomy, new species, Japan

\begin{abstract}
The Japanese species of Asteiidae are revised. Six species of Asteia Meigen, 1830, are recorded here in addition to Astiosoma okinawae Sabrosky, 1957, hitherto recorded from Japan. Among them, Asteia gemina, A. longistylus, A. lunaris, and A. nigrigena are described as new to science. Asteia angustipennis Duda, 1934, and A. megalophthalma Duda, 1927, are recorded from Japan for the first time. There are conspicuous morphological differences in the male and female genitalia of the seven species of Asteia. It is suggested that Asteia angustipennis, A. concinna, and A. gemina are very closely related and may be reproductively isolated because of their body markings and male genitalia. These species are assigned to the concinna group of Asteia, newly designated in this study. A key to Japanese species and distribution maps are provided.
\end{abstract}

\section{INTRODUCTION}

The Asteiidae are a small family consisting of approximately 100 species and 11 genera (Sabrosky, 1987; Yang \& Zhang, 1996). Adults are found in open or wooded grassy areas (e.g. marshes, forests), and larvae are known as saprophagous, associated with fungi and rotting woods (Ferrar, 1987; Papp, 1992).

Asteiid flies have been recorded from all zoogeographical regions. The asteiid fauna of the Palaearctic Region is well-known, comprising 41 species assigned to four genera (Papp, 1984; Yang \& Zhang, 1996; CarlesTolrá, 1998). Among them, 19 species and four genera are recorded from the area around Japan, such as Mongolia, China, Korea, and the Far East of Russia (Duda, 1934; Papp, 1972, 1974; Yang \& Zhang, 1996). Tamaki (1997) and Kubo (2000) reported an undetermined species of Asteia Meigen, 1830, from Honshu (Japan). From the Oriental Region, 11 species in three genera and an undetermined species of Phlebosotera Duda, 1927, are known. Among them, six species of Asteia and Astiosoma okinawae Sabrosky, 1957, have been recorded from Taiwan and the Ryukyus (Japan), respectively (Sabrosky, 1977). The knowledge of the Japanese fauna of Asteiidae is based on the original records for Astiosoma okinawae and undetermined species. However, it was expected that more species would be found in Japan, because there are 25 species in adjacent countries.

In this paper the results of a taxonomic study of Japanese materials is presented. In addition to the Astiosoma okinawae, six species of Asteia are recognized based on the specimens collected throughout Japan. Among them, four species of Asteia are described as new to science and the other two species are recorded from Japan for the first time. Male and female genitalia of the species of Asteia are compared, and the diversity and usefulness of these structures for classification and reproductive isolation within the genus are discussed.

\section{MATERIALS AND METHODS}

This study is based on 90 dried specimens. External structures were observed under a stereoscopic microscope. Male and female abdomens were treated with $10 \% \mathrm{KOH}$ solution at $40^{\circ} \mathrm{C}$ for 10 hours, stained with Chlorazol Black E, and then observed in pure glycerol. Dissected parts of an abdomen were preserved in pure glycerol in a plastic microvial pinned under the specimen. Right or left wings of the holotypes and other specimens were slide-mounted in Euparal.

Body length was measured between the anterior apex of the head and the posterior margin of the abdomen, and wing length between the base of the costa and the apex of vein $R_{4+5}$.

All specimens examined have a serial number labels attached and are deposited in the Biosystematics Laboratory, Graduate Institute of Social and Cultural Studies, Kyushu University, Fukuoka (BLKU) (As.1001-1040, 1045-1049, 1054-1056, 10581069, 1071-1072, 1080-1084), the Forestry and Forest Products Research Institute, Tsukuba (FFPRI) (As.1041-1044, 1050-1053, 1057, 1076-1079) and in Tamaki's personal collection (As.2013-2019). All type specimens are deposited in the first two depositories. Abbreviations of locality are as follows: C - City, P - Prefecture, T - Town, V - Village. Species with an asterisk are newly recorded from Japan.

The terminology and abbreviations mainly follow McAlpine (1981), but the following terms are also used in this study: interfrontal stripe (Sabrosky, 1956), postpedicel (Stuckenberg, 1999; 1st flagellomere: McAlpine, 1981), surstylus (Cumming et al., 1995; posterior surstylus: McAlpine, 1981), phallapodeme (Cumming et al., 1995; aedeagal apodeme: McAlpine, 1981), postgonite (Cumming et al., 1995; paramere: McAlpine, 1981), phallus (Cumming et al., 1995; aedeagus: McAlpine, 1981), 10th abdominal tergite (Griffiths, 1981), epiproct (McAlpine, 1981), 10th abdominal sternite (Griffiths, 1981; hypoproct: McAlpine, 1981), and intracellular canaliculi (Theodor, 1976).

Abbreviations for thoracic chaetotaxy are as follows: $d c-$ dorsocentral seta; kepst - katepisternal seta; $n p l$ - notopleural seta; pal - postalar seta; prst - presutural supra-alar seta; sctl scutellar to seta. The abdominal tergites and sternites are abbreviated $\mathrm{T}$ and $\mathrm{S}$, respectively. Abbreviations for the figures are as follows: c - cercus; $\mathrm{d}$ - spermathecal duct; ep - epandrium; hyp - hypandrium; is - interfrontal stripe, iv - inner vertical seta; $\mathrm{L}$ - left lateral sclerite of distiphallus; oc - ocellar seta; or - 


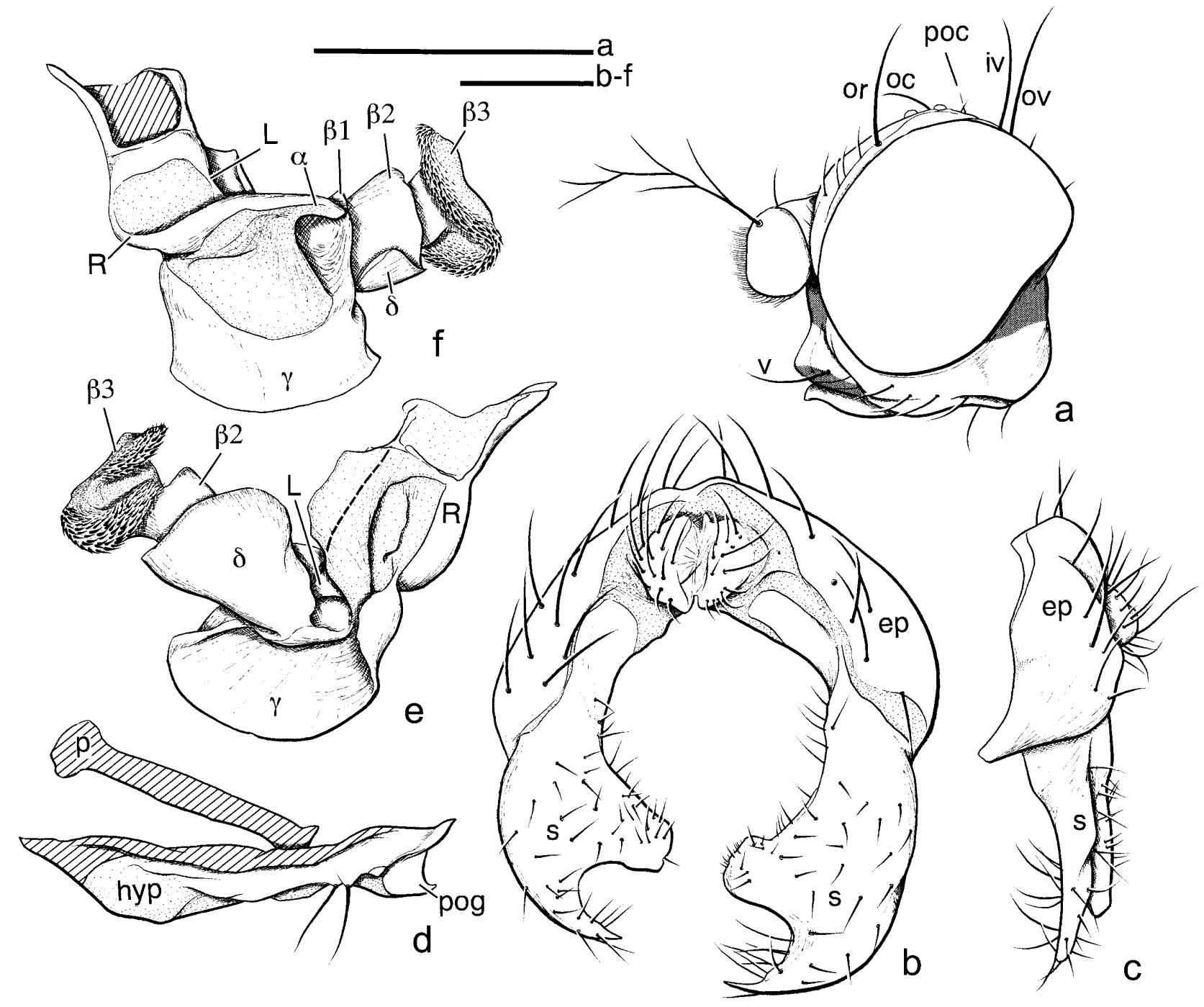

Fig. 1. Male (As.1025) of Asteia angustipennis Duda, 1934. a - head in left lateral view; b - epandrial complex (epandrium, surstylus, and cerci) in caudal view; c - epandrial complex in left lateral view; d - hypandrial complex (hypandrium, gonites, and phallapodeme) in left lateral view; e - distiphallus in left lateral view; $\mathrm{f}-$ distiphallus in right lateral view. Scale bars: $\mathrm{a}=0.50 \mathrm{~mm}$; $\mathrm{b}-\mathrm{f}=0.10 \mathrm{~mm}$. Refer to the text for the abbreviations.

orbital seta: ov - outer vertical seta; $\mathrm{p}$ - ventral pocket of vagina; poc - postocellar seta; pog - postgonite; $\mathrm{R}$ - right lateral sclerite of distiphallus; $\mathrm{s}-$ surstylus; $\mathrm{S} 7,8,10-7$ th, 8 th and 10 th abdominal sternites; T7, 8, $10-7$ th, 8th and10th abdominal tergites; $\mathrm{v}$ - vibrissa; vf - ventral floor of vagina; $\mathrm{vg}$ - vagina; vr - ventral receptacle; $\alpha$ - apical projection of right lateral sclerite; $\beta 1-3$ - folds of apex of distiphallus; $\gamma$ - curtainlike sclerite of left lateral sclerite; $\delta$ - plate of left lateral sclerite; I - narrow section of spermathecal duct; II - expanded section of spermathecal duct; III - spermatheca.

\section{TAXONOMY}

\section{Asteia angustipennis Duda, 1934*}

(Figs 1a-f, 2a, 3a, 4a-d, 5)

Asteia angustipennis Duda, 1934: 11.

Specimens examined. [HOKKAIDO] 4 t, Miyaginosawa, Sapporo C, 27.vii.1996 (As.1001-1003, 1035); 1 ठे, Misumai, Sapporo C, 28.vii.1996 (As.1004). [HONSHU] Yamanashi P: 4 o 2 ㅇ, Yunosawa Pass, Yamato V, 17.vii.2001 (As.1005-1010); 1 ․, Kanayama, Sudama T, 4.viii.1995 (As.1011); 1 ㅇ, same locality, 30.viii.1996 (As.1012); $2 \lesssim 1 \%$, Norogawadeai, Ashiyasu V, 1.viii.1997 (As. 1013-1015); 10 o 10 ㅇ, same locality, 19.viii.2001 (As.1016-1032, 1062-1064).

Distribution. Russia (Duda, 1934), Mongolia (Papp, 1972), and Japan (Hokkaido and Honshu: Fig. 5).

Remarks. This species is distinguished from other congeners by the following characters: arista with long branches (Fig. 1a); interfrontal stripe of male extended anteriorly to anterior $1 / 4$ of frons (Fig. $2 \mathrm{a}$ : is); face with white transverse band (Fig. 1a); 2 pairs of dorsocentral setae present; 2 notopleural setae present; scutellum yellow in ground colour, with semicircular dark brown marking dorsally.

\section{Asteia gemina sp.n.}

(Figs 2b, 3b, 5, 6a-e, 7a-d)

\section{Description}

Male. Head (Fig. 6a) higher than long; frons yellow brown in ground colour, dark brown along interfrontal stripe, with fine setulae along interfrontal stripe, eye 

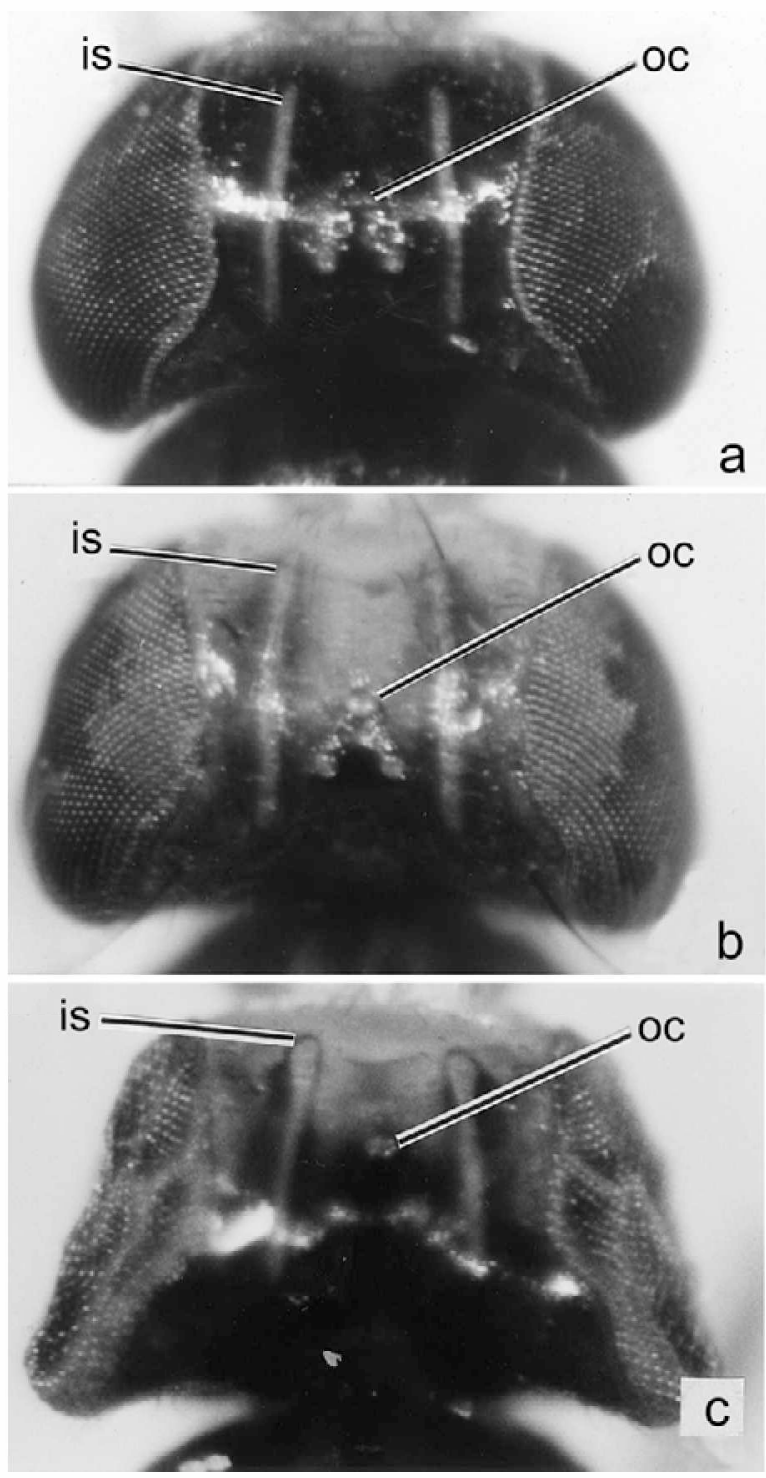
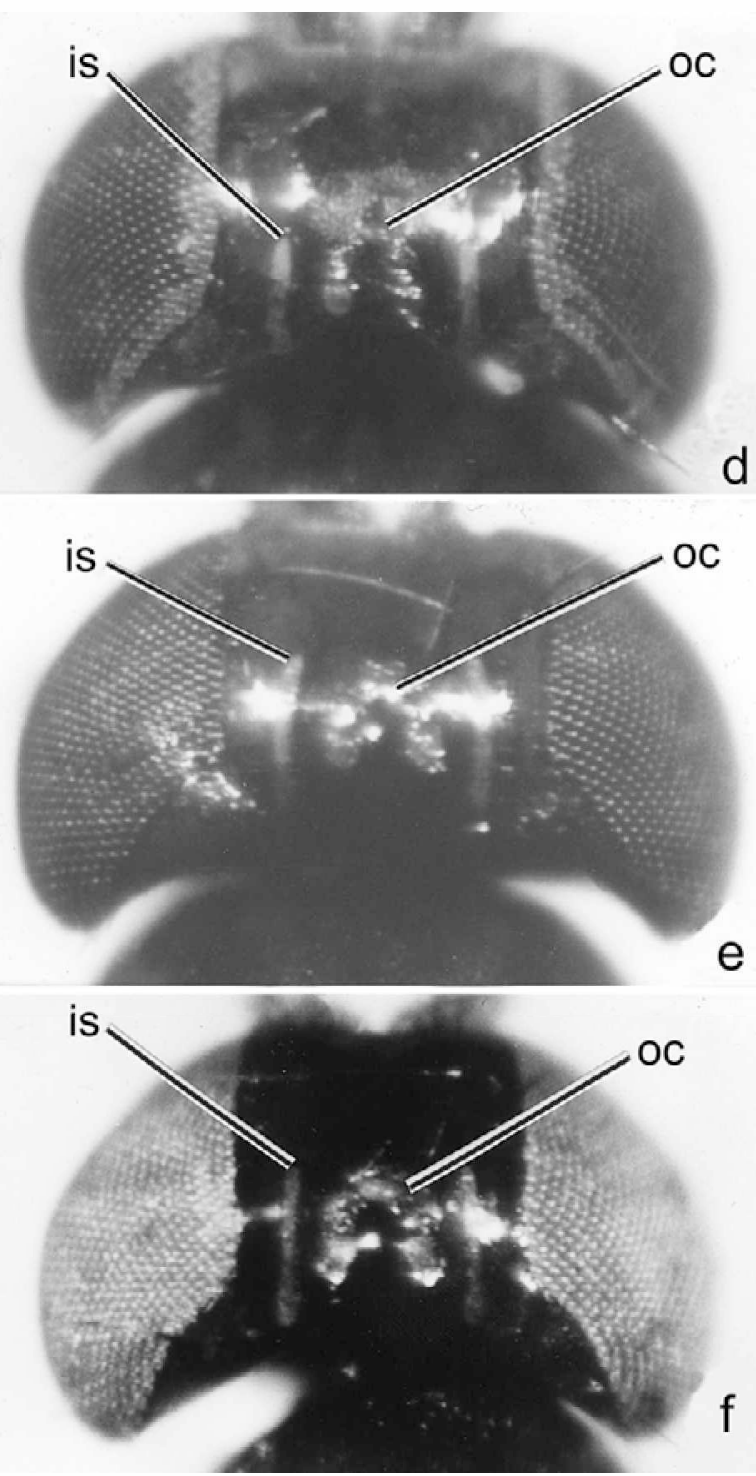

Fig. 2. Head of male Asteia Meigen, 1830, in dorsal view. a - Asteia angustipennis Duda, 1934 (As.1025); $\mathrm{b}-$ A. gemina sp. $\mathrm{n}$. (holotype); $\mathrm{c}-A$. concinna Meigen, 1830 (As.1085); $\mathrm{d}-$ A. longistylus sp. $\mathrm{n}$. (holotype); e - A. lunaris sp. $\mathrm{n}$. (holotype); $\mathrm{f}-A$. nigrigena sp. n. (holotype). Refer to the text for the abbreviations.

margin and anterior margin; orbital plate, ocellar triangle and vertex dark brown in ground colour, polished; anterior apex of interfrontal stripe reaching anterior $1 / 3$ of frons (Fig. 2b: is); face dark yellow in ground colour, with black marking at lateroventral corner; parafacial and gena yellow; occiput and dorsal half of postgena dark brown; ventral half of postgena yellow. Head chaetotaxy: 1 orbital, 1 ocellar, 1 inner vertical, 1 outer vertical, 1 vibrissal, 5 subvibrissal s, all black; 1 genal and several postgenal setae yellow; postocellar seta present. Scape, pedicel and postpedicel yellow in ground colour; arista black, with 4 dorsal and 3 ventral branches; pedicel with long seta dorsally; postpedicel covered with white setulae. Mouth parts yellow.

Thorax entirely dark brown dorsally and yellow ventrally in ground colour; mesonotum entirely dark brown except yellow postalar wall; scutellum yellow in ground colour, with dark brown semicircular marking dorsally; propleural lobe and notopleuron dark brown; other thoracic pleura yellow in ground colour, without dark markings. Thoracic chaetotaxy: $2 \mathrm{dc}, 2 \mathrm{npl}, 2$ kepst and $1 \mathrm{sctl}$ all black; 6 minute $d c$ anterior to large $d c$ present; minute setula anterior to sctl present.

Wing (Fig. 3b) hyaline, 3.5 times longer than wide; veins pale brown; costal section between apices of $R_{1}$ and $\mathrm{R}_{2+3}$ longer than $\mathrm{R}-\mathrm{M}$ crossvein; apex of vein $\mathrm{CuA}_{1}$ reaching posterior margin of wing. Halter entirely yellow.

Legs entirely yellow.

Abdomen yellow in ground colour, abdominal tergites slightly darkened with pale brown, without distinct dark brown marking; abdominal sternites entirely yellow. Genitalia (Fig. 6b-e): epandrium (Fig. 6b-c: ep) short; 

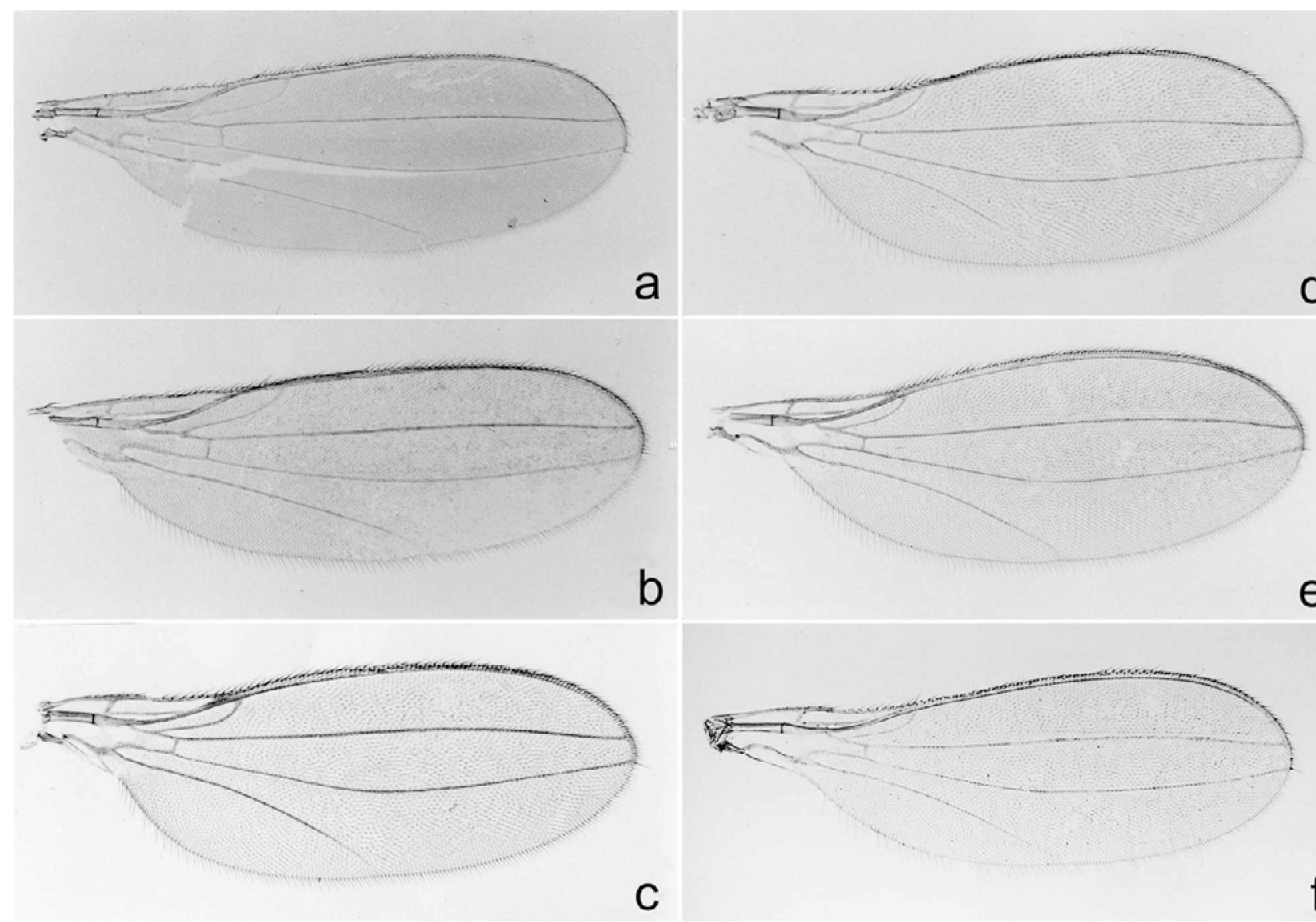

d

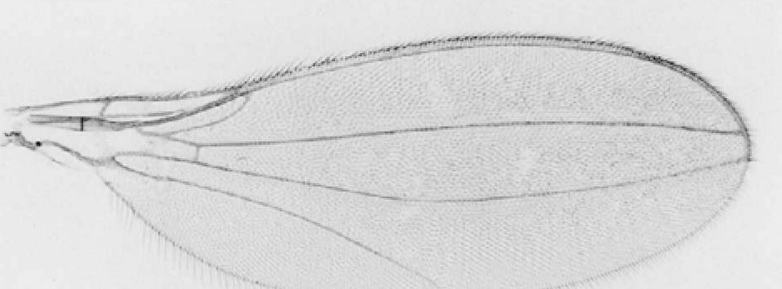

b

e

Fig. 3. Wings of Japanese Asteia Meigen, 1830. a - Asteia angustipennis Duda, 1934 (As. 1025); b - A. gemina sp. n. (holotype); c - A. longistylus sp. n. (holotype); d - A. lunaris sp. n. (holotype); e - A. megalophthalma Duda, 1927 (As.1068); $\mathrm{f}-A$. nigrigena sp. n. (holotype).

both surstyli similar in shape and size, surstylus bifid, subapical process broad with blunt apex, apical process narrowed and pointed; hypandrium with small postgonite (Fig. 6d: pog) and 2 setae anterior to postgonite; basiphallus cylindrical; distiphallus (Fig. 6d-e) consisting of lateral sclerites: right lateral sclerite (Fig. 6d-e: R) prolonged, bent anteriorly and projected as spine-like process (Fig. 6d-e: $\alpha$ ), left lateral sclerite (Fig. 6d-e: L) prolonged and bent anteriorly, bearing curtain-like sclerite (Fig. 6d-e: $\gamma$ ), and plate-like sclerite (Fig. 6d-e: $\delta$ ) supporting apical part of distiphallus; apical part of distiphallus bearing series of spiral folds, apical half of fold membranous, bearing numerous, spine-like intracellular canaliculi (Fig. 6d-e: $\beta 1-3$ ).

Body length $2.5 \mathrm{~mm}$. Wing length $2.1 \mathrm{~mm}$; width 0.7 $\mathrm{mm}$.

Female similar to male in appearance except postabdominal structures: T6-8 and S6-8 broad plate-like; T8 and S8 shorter than T7 and S7 (Fig. 7a); T10 and S10 triangular; cercus as long as T10 (Fig. 7a). Genitalia: anterior $3 / 5$ of vagina 3 times wider laterally and 2 times wider dorsoventrally than posterior $2 / 5$ (Fig. $7 \mathrm{~b}$ : vg); ventral receptacle (Fig. 7b: vr) membranous, spherical in shape. Two spermathecae present: spermathecal duct consisting of posteriorly narrowed (Fig. 7d: I) and anteriorly expanded sections (Fig. 7d: II); distal half of expanded section spindle-like; spermatheca (Fig. 7d: III) as long as body of dilated section, with numerous intracellular canaliculi.

Type material. Holotype 8 : "Obuchinuma / Rokkasho Vil. / 2.viii.1996 / M.Sueyoshi leg.", "As.1069”, lime green circle, "Holotype / Asteia / gemina / Sueyoshi" (red label) (BLKU). Paratypes 8 or 9 . [HOKKAIDO] 2 , Miyaginosawa, Sapporo C, 27.vii.1996 (As.1033-1034). [HONSHU] Aomori P: 6 \& 9 웅, same data as holotype (As. 1036-1049, 1061).

Etymology. The specific epithet refers to its similar appearance to $A$. concinna Meigen, 1830.

Distribution. Japan (Hokkaido and Honshu: Fig. 5).

Remarks. This species is distinguished from congeners by the following characters: arista with long branches (Fig. 6a); interfrontal stripe on male extending anteriorly to anterior $1 / 4$ of frons (Fig. 2b); face yellow in ground colour, with pair of black markings on lateroventral side (Fig. 6a); 2 pairs of dorsocentral setae present; 2 notopleural setae present; scutum yellow brown except 2 pairs of longitudinal yellow brown areas; scutellum yellow in ground colour, with semicircular dark brown marking dorsally. It is very similar to $A$. concinna and difficult to distinguish from the latter species based on most of the male and female genitalia (Figs 6b-e, 7b-d, $8 \mathrm{~b}-\mathrm{e})$. However, A. gemina differs from A. concinna in 

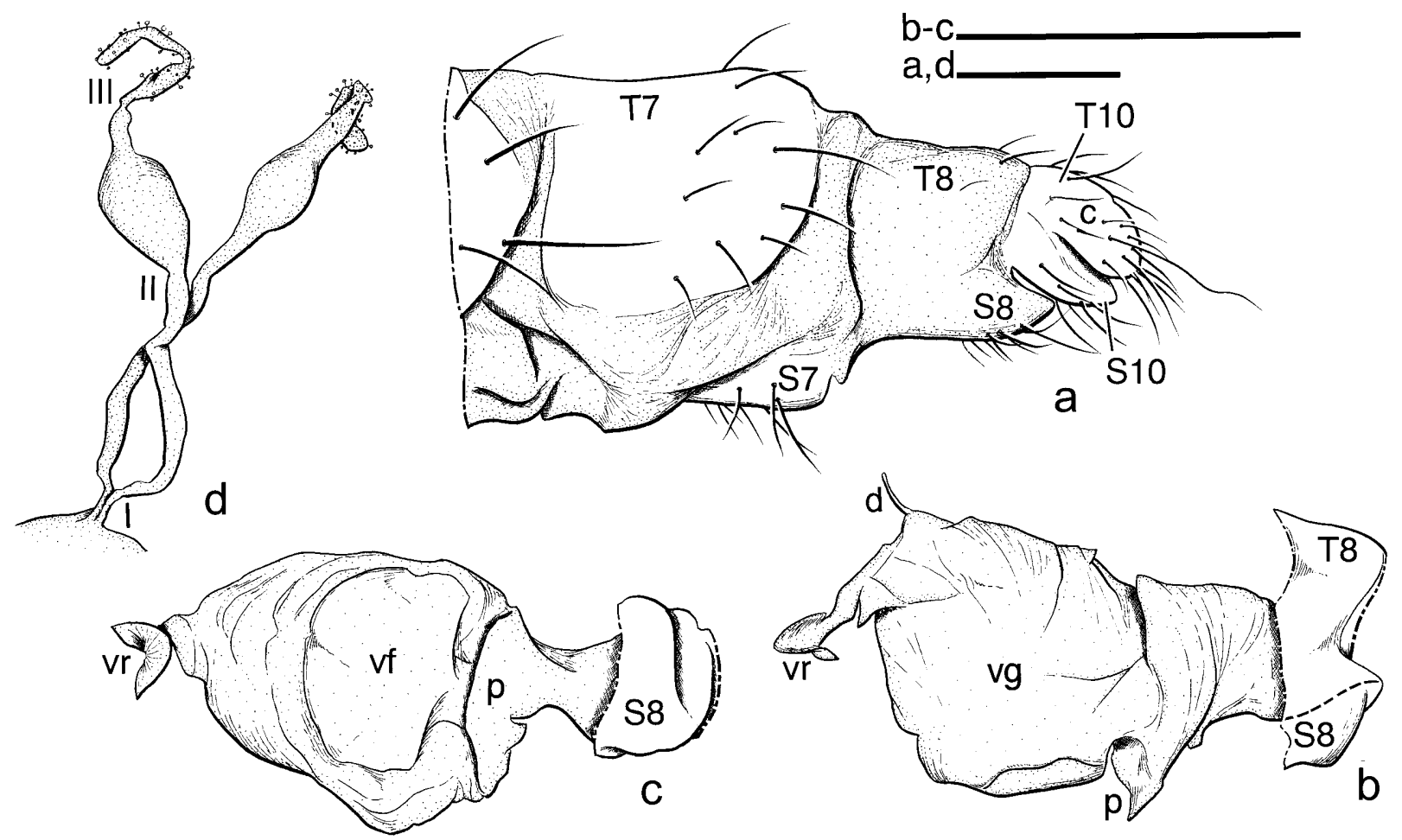

Fig. 4. Female (As. 1064) of Asteia angustipennis Duda, 1934. a - postabdomen in left lateral view; $b$ - genitalia in left lateral view; $\mathrm{c}-$ genitalia in ventral view; $\mathrm{d}$ - spermathecae and spermathecal ducts. Scale bars: $\mathrm{a}=0.15 \mathrm{~mm} ; \mathrm{b}-\mathrm{c}=0.33 \mathrm{~mm} ; \mathrm{d}=0.10 \mathrm{~mm}$. Refer to the text for the abbreviations.
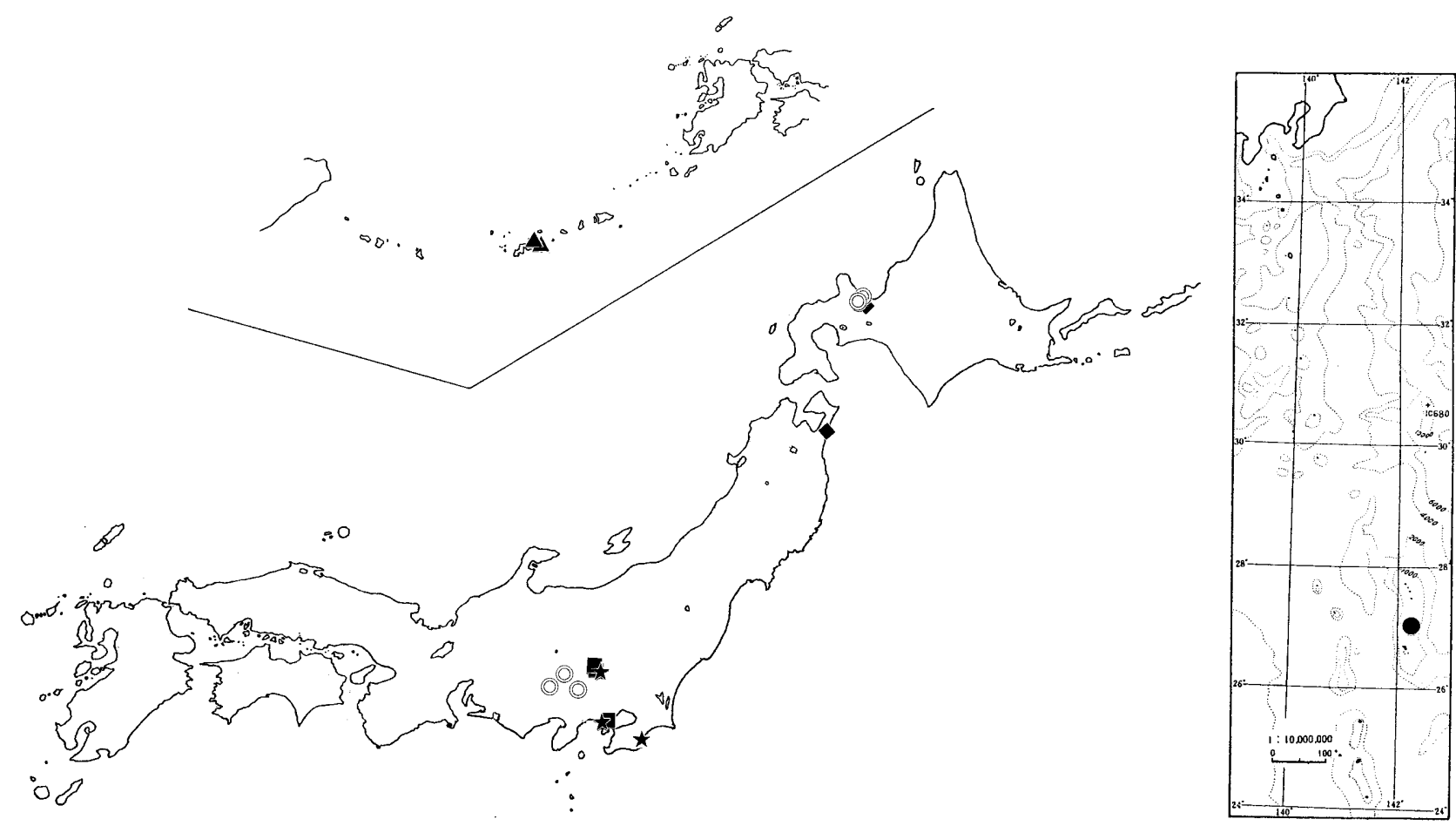

Fig. 5. Distribution map of Japanese Asteia Meigen, 1830. Double circles - Asteia angustipennis Duda, 1934; $\bullet$ A. gemina sp. n.; - A. longistylus sp. n.; A. lunaris sp. n.; $\boldsymbol{\Delta}$ A. megalophthalma Duda, 1927; $\star$ A. nigrigena sp. n. 


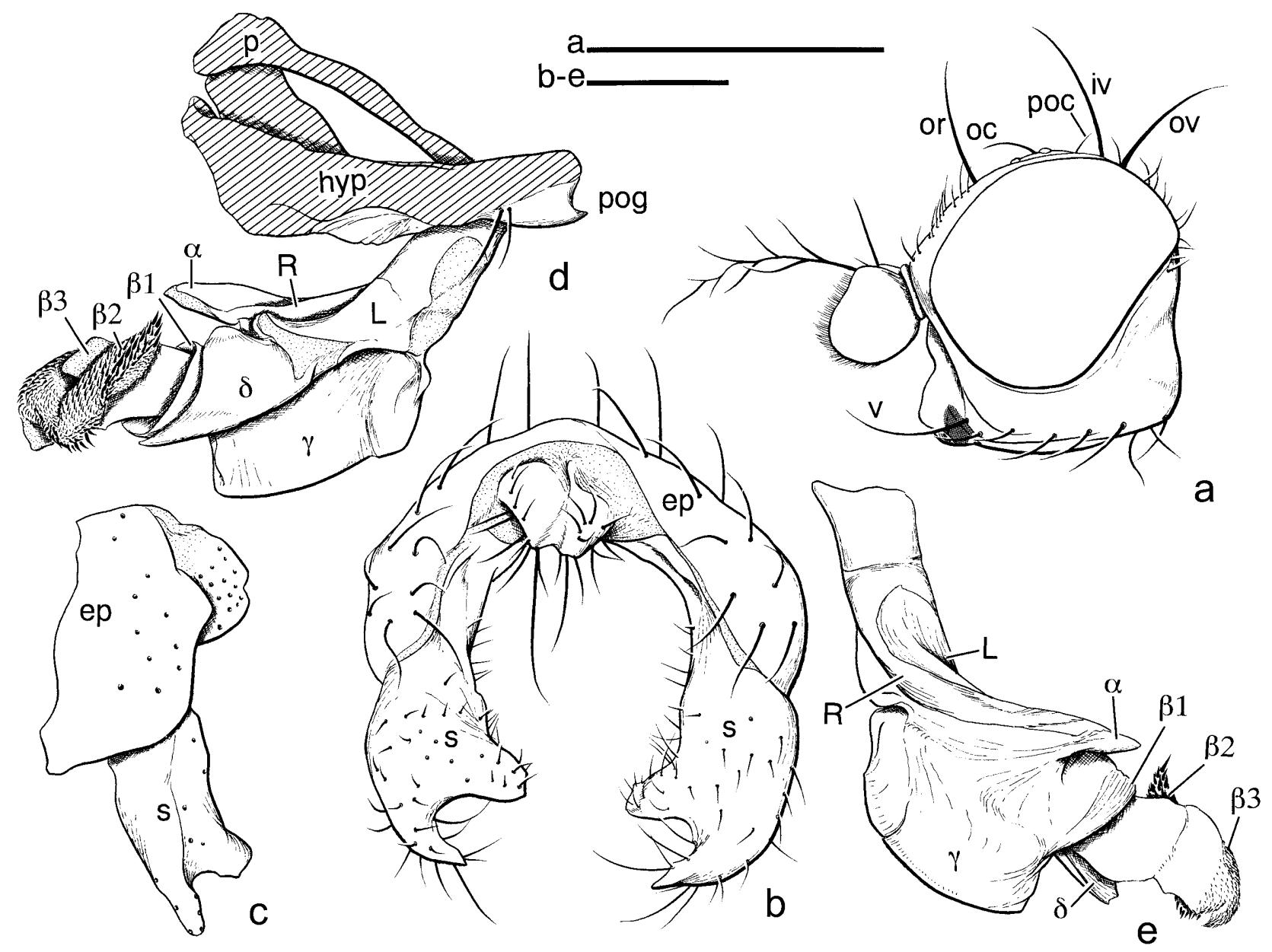

Fig. 6. Male (holotype) of Asteia gemina sp. n. a - head in left lateral view; b-epandrial complex in caudal view; c-epandrial complex in left lateral view; $d$-hypandrial complex and phallus in left lateral view; $\mathrm{e}$ - distiphallus in right lateral view. Scale bars: $\mathrm{a}=0.50 \mathrm{~mm} ; \mathrm{b}-\mathrm{e}=0.10 \mathrm{~mm}$. Refer to the text for the abbreviations.

that the male distiphallus bears a broad curtain-like sclerite (Fig. 6d-e: $\gamma$ ).

\section{Asteia longistylus sp.n.}

(Figs 2d, 3c, 5, 9a-d, 10a-d)

\section{Description}

Male. Head (Fig. 9a) higher than long; frons dark brown except yellow brown anterior $1 / 4$, entirely bare; orbital plate and ocellar triangle dark brown in ground colour, polished; anterior apex of interfrontal stripe reaching anterior margin of anterior ocellus but not beyond it (Fig. 2c); face dark brown in ground colour, with white transverse band on ventral half; parafacial dark brown; gena yellow; occiput and dorsal half of postgena dark brown; ventral half of postgena yellow. Head chaetotaxy: 1 orbital, 1 ocellar, 1 inner vertical, 1 outer vertical, 1 postocellar, 1 vibrissal, 4 subvibrissal, 1 genal and several postgenal setae all black; 2 minute setulae anterior to orbital seta present. Scape and pedicel of antenna dark brown in ground colour, postpedicel yellow brown in ground colour, dorsal $1 / 3$ of postpedicel dark brown; arista black, with 3 dorsal and 2 ventral branches; pedicel with long seta dorsally; postpedicel covered with white setulae. Mouth parts yellow.
Thorax entirely yellow in ground colour, with dark brown markings; mesonotum entirely dark brown except yellow postalar wall, scutellum entirely yellow; propleural lobe and notopleuron dark brown; thoracic pleura yellow in ground colour, katepisternum and katepimeron without dark markings. Thoracic chaetotaxy: $2 d c$, $1 \mathrm{prst}, 1 \mathrm{pal}, 2 \mathrm{npl}, 2 \mathrm{kepst}$, and $1 \mathrm{sctl}$ all black; 3 minute $d c$ present posterior to transverse suture; prst as short as $d c$ posterior transverse suture; minute setula present anterior to sctl.

Wing (Fig. 3c) hyaline, 3 times longer than wide; veins pale brown; costal section between apices of $\mathrm{R}_{1}$ and $\mathrm{R}_{2+3}$ shorter than R-M crossvein; apex of vein $\mathrm{CuA}_{1}$ close to posterior margin of wing but not reaching it. Halter yellow, knob dark brown.

Legs entirely yellow.

Abdomen yellow in ground colour, abdominal tergites slightly pale brown; T5 with pair of dark brown markings; abdominal sternites entirely yellow. Genitalia (Fig. 9b-d): epandrium (Fig. 9b-c: ep) short anteroposteriorly; surstylus slender, with short posterior process; hypandrium with postgonite (Fig. 9c: pog) with rounded apex; basiphallus cylindrical, pointed posteriorly; distiphallus (Fig. 9d) coiled, consisting of basal tube laterally 


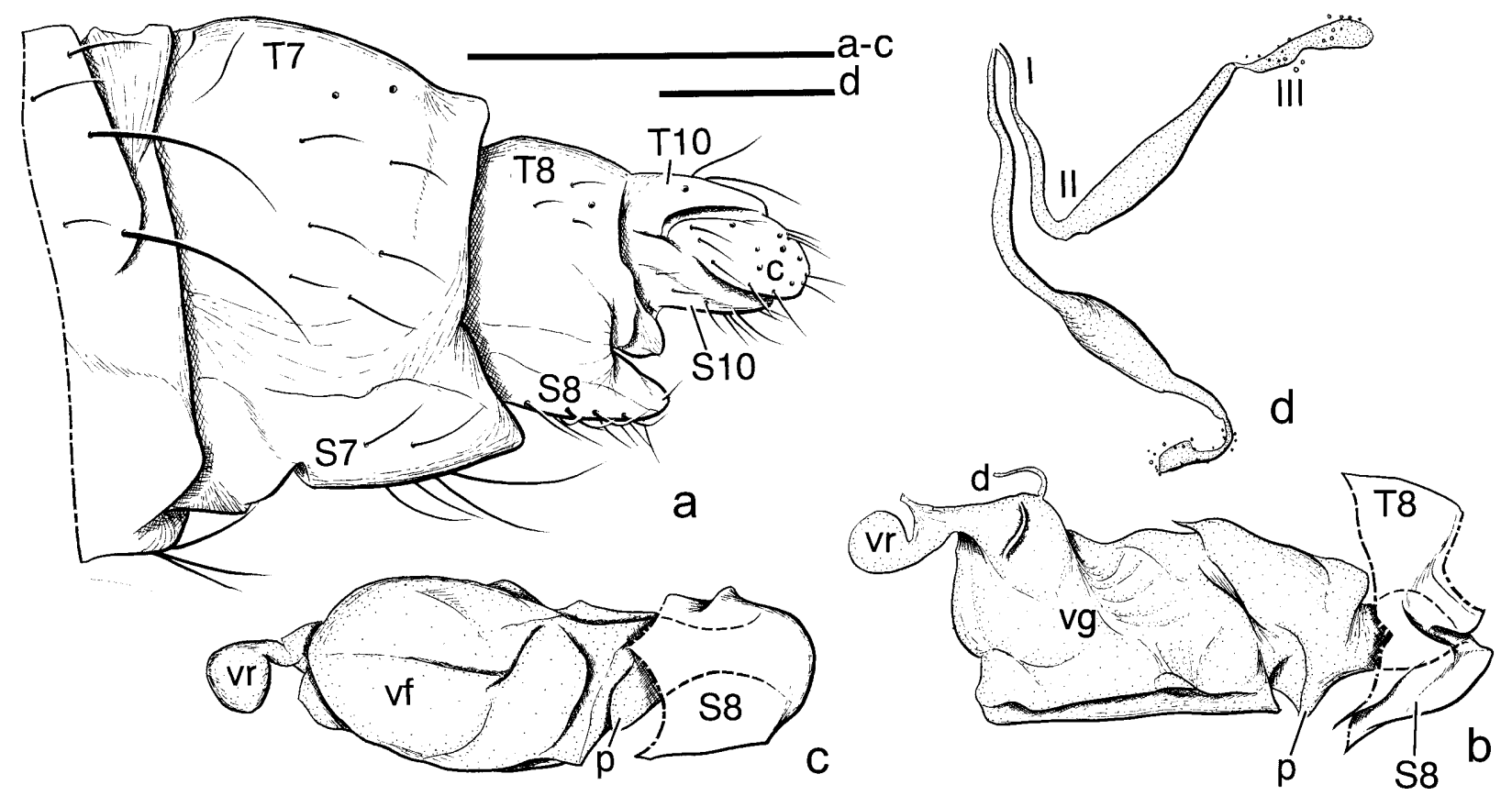

Fig. 7. Female (As. 1061) of Asteia gemina sp. n. a - postabdomen in left lateral view; b-genitalia in left lateral view; c - genitalia in ventral view; $d$ - spermathecae and spermathecal ducts. Scale bars: $a=0.25 \mathrm{~mm} ; b-c=0.33 \mathrm{~mm} ; d=0.10 \mathrm{~mm}$. Refer to the text for the abbreviations.

sclerotized, mesal complex tube and apical slender wirelike process.

Body length $2.1 \mathrm{~mm}$; wing length $2.1 \mathrm{~mm}$, width 0.7 mm.

Female similar to male in appearance except postabdominal structures: T6-8 and S6-8 broad plate-like; pair of triangular membranous sacs projected from posterior margin of T6, extending over anterior margin of T7 (Fig. 10a-b); T8 and S8 shorter than T7 and S7 (Fig. 10a-b); $\mathrm{T} 10$ and S10 triangular; cercus as long as T10 and rightangled triangular in dorsal view (Fig.10a-b). Genitalia: vagina (Fig. 10c: vg) broadened anteriorly, widest at anterior 2/5; ventral receptacle (Fig. 10c: vr) cylindrical, crooked, appendix-like in shape, as long as half of vagina. Two spermathecae present: spermathecal duct consisting of posteriorly narrowed (Fig. 10d: I) and anteriorly expanded sections (Fig. 10d: II); anterior half of expanded section spindle-like, shorter than narrowed section; spermatheca (Fig. 10d: III) covered with numerous intracellular canaliculi, 2 times longer than expanded section of spermathecal duct.

Type material. Holotype $\delta$ : "Kitafukurozawa / Ogasawara Vil. / Tokyo / Chichijima Japan / 30.xi.2001 / M.Sueyoshi leg.", "As.1066", lime green circle, "Holotype / Asteia / longistylus / Sueyoshi" (red square label) (BLKU). Paratypes 6 o 3 q. [OGASAWARA] 5 क 3 \%, same data as holotype (As.10501056, 1067); 1 \%, same locality, 30.vi.2002 (As.1084).

Etymology. The specific epithet refers to the long surstylus. Distribution. Japan (Ogasawara: Fig. 5).

Remarks. This species is distinguished from other congeners by the following characters: arista with long branches (Fig. 9a); interfrontal stripe of male extended anteriorly to anterior ocellus (Fig. 2d: is); face with white transverse band (Fig. 9a); 2 pairs of dorsocentral setae present; scutellum entirely yellow; katepisternum without dark marking; abdominal tergites of male lacking dark markings except 5 th abdominal tergites with pair of dark markings. It is very similar to $A$. chinica Yang \& Zhang, 1996 , in appearance but differs from it by wing veins $R_{1}$ and $R_{2+3}$ very close, length between apices of them shorter than R-M crossvein (Fig. 3c), knob of halter dark brown, and 1-4th abdominal tergites of male lacking dark markings. It is also similar to A. megalophthalma Duda, 1927, but differs from the latter in the absence of postocellar seta (Fig. 9a), katepisternum and katepimeron without dark markings, and 5th abdominal tergite with paired dark markings.

\section{Asteia lunaris sp.n.}

(Figs 2e, 3d, 5, 11a-c)

\section{Asteia sp.; Tamaki, 1997: 148. (in part.)}

\section{Description}

Male. Head (Fig. 11a) higher than long; anterior half of frons yellow brown, posterior half dark brown, entirely bare; orbital plate and ocellar triangle dark brown in ground colour, polished; anterior apex of interfrontal stripe slightly beyond anterior ocellus (Fig. 2e: is); face dark brown in ground colour, with white transverse band on ventral half; parafacial and gena dark brown; occiput and dorsal half of postgena dark brown; ventral half of postgena yellow. Head chaetotaxy: 1 orbital, 1 ocellar, 1 inner vertical, 1 outer vertical, 1 vibrissal, 2 subvibrissal, 1 genal and several postgenal setae all black; postocellar seta absent; minute setula present anterior to orbital seta. Scape and pedicel of antenna dark brown in ground colour; postpedicel yellow brown in ground colour, dorsal 


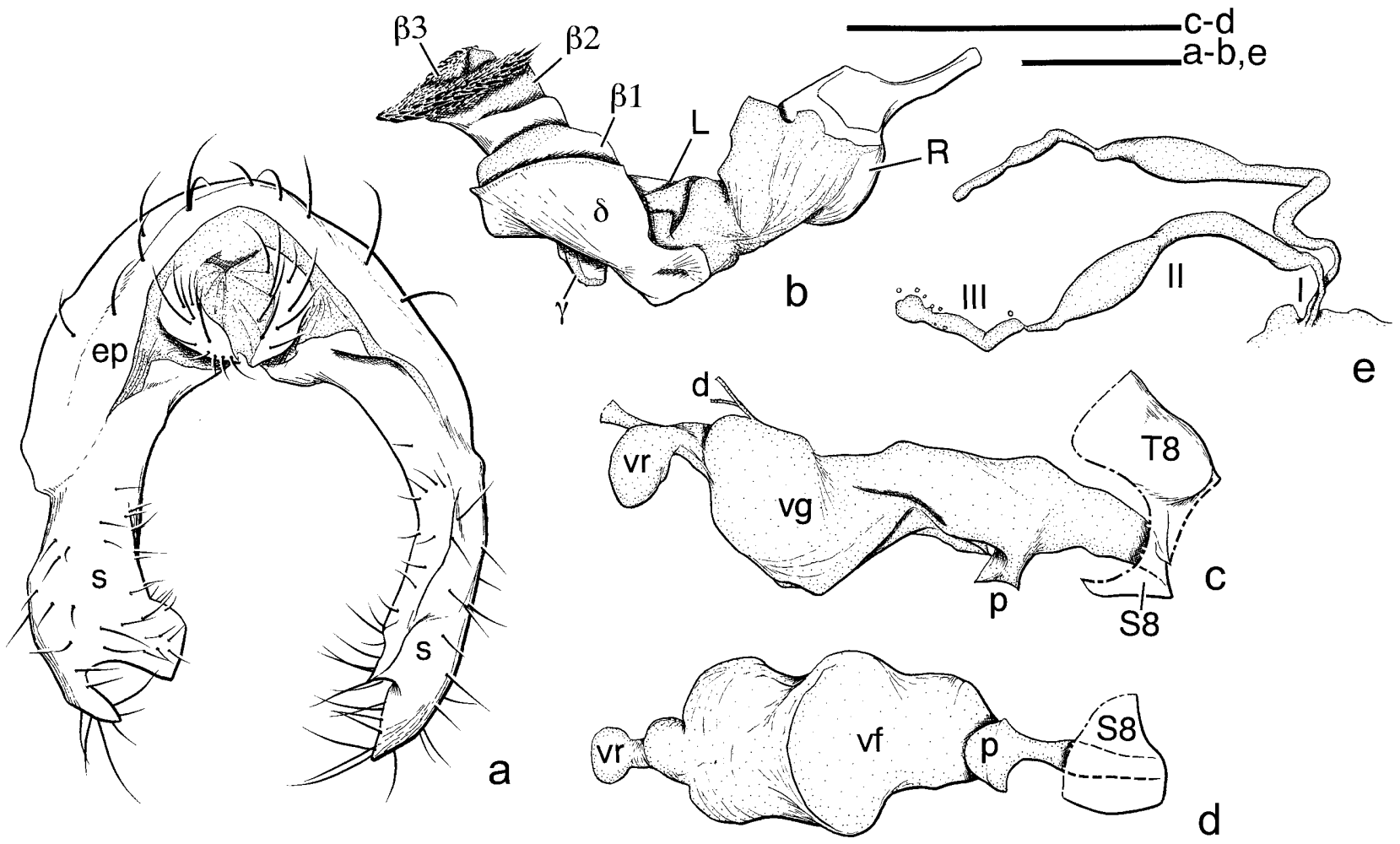

Fig. 8. Asteia concinna Meigen, 1830. a - epandrial complex in caudal view; b - distiphallus in left lateral view; $\mathrm{c}-\mathrm{genitalia}$ in left lateral view; $d$ - genitalia in ventral view; e - spermathecae and spermathecal ducts. a-b - male (As. 1085); c-e - female (As. 1086). Scale bars: $a-b, e=0.10 \mathrm{~mm} ; \mathrm{c}-\mathrm{d}=0.33 \mathrm{~mm}$. Refer to the text for the abbreviations.

1/3 of postpedicel dark brown; arista black, with 3 dorsal and 2 ventral branches; pedicel with long seta dorsally; postpedicel covered with white setulae. Mouth parts yellow.

Thorax entirely yellow in ground colour, with dark brown markings; mesonotum entirely dark brown except yellow postalar wall, scutellum entirely yellow; propleural lobe and notopleuron dark brown; thoracic pleura yellow in ground colour, katepisternum and katepimeron with longitudinal dark brown markings. Thoracic chaetotaxy: 2 dc, 1 pal, $2 \mathrm{npl}, 2$ kepst and 1 sctl all black; 3 minute $d c$ present posterior to transverse suture; minute setula present anterior to sctl.

Wing (Fig. 3d) hyaline, 3 times longer than wide; veins pale brown; costal section between apices of $R_{1}$ and $R_{2+3}$ shorter than R-M crossvein; apex of vein $\mathrm{CuA}_{1}$ close to posterior margin of wing but not reaching it. Halter yellow, knob dark brown.

Legs entirely yellow.

Abdomen yellow in ground colour, abdominal tergites slightly pale brown; T5 with broad transverse dark brown marking; abdominal sternites entirely yellow. Genitalia (Fig. 11b-c): epandrium (Fig. 11b: ep) short; surstylus with blunt posterior process; hypandrium with postgonite; basiphallus cylindrical, pointed posteriorly; distiphallus (Fig. 11c) coiled, consisting of basal tube laterally sclerotized, mesal complex tube and apical slender wire-like process.

Body length $1.5 \mathrm{~mm}$; wing length $2.1 \mathrm{~mm}$, width 0.7

\section{Female unknown.}

Type material. Holotype o: "Mt.Enkai / Yokohama City / Kanagawa Pref. / Honshu Japan / 19.ix.2000 / M.Sueyoshi leg.", "As.1065", lime green circle, "Holotype / Asteia / lunaris / Sueyoshi" (red square label) (BLKU). Paratypes 3 o. [HONSHU] 1 o, same data as holotype (As.1057). Saitama P: 1 t, Iwai, Moroyama T, 24.vi.1995 (As.2017); 1 ô, Nakaomaeda, Yorii T, 4.v.1984 (As.2013)

Etymology. The specific epithet refers to the crescent marking on the katepisternum.

Distribution. Japan (Honshu: Fig. 5).

Remarks. This species is distinguished from other congeners by the following characters: interfrontal stripe of male extended anteriorly to anterior ocellus (Fig. 2e: is); face with white transverse band (Fig. 11a); 2 pairs of dorsocentral setae present; scutellum entirely yellow; katepisternum with dark marking; abdominal tergites of male lacking dark markings except 5 th abdominal tergite with transverse dark marking. It is very similar to $A$. chinica in appearance but differs from it in wing veins $\mathrm{R}_{1}$ and $R_{2+3}$ being very close, length between apices of them shorter than R-M crossvein (Fig. 3d), knob of halter dark brown, 1-4th abdominal tergites of male lacking dark markings, and 5th abdominal tergite of male with unpaired transverse dark marking.

Tamaki (1997) reported an undetermined species of Asteia from Saitama Prefecture, Japan. I examined this series of the specimens and found that one of them belongs to this species. 


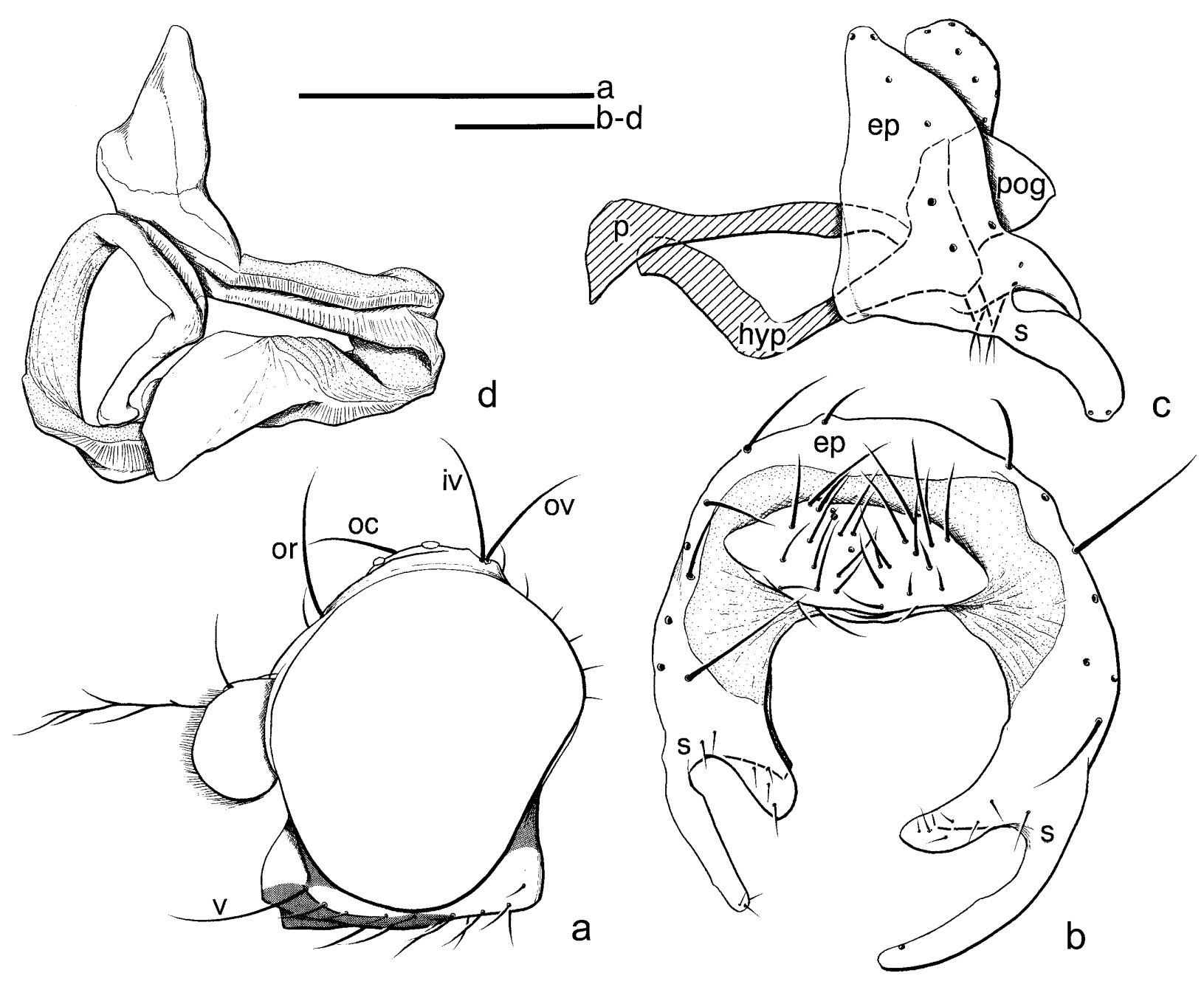

Fig. 9. Male (holotype) of Asteia longistylus sp. n. a - head in left lateral view; b - epandrial complex in caudal view; $\mathrm{c}-$ epandrial and hypandrial complex in left lateral view; $d$-distiphallus in left lateral view. Scale bars: $a=0.30 \mathrm{~mm} ; \mathrm{b}-\mathrm{d}=0.05 \mathrm{~mm}$. Refer to the text for the abbreviations.

\section{Asteia megalophthalma Duda, 1927*}

(Figs 3e, 5, 12a-c)

Asteia megalophthalma Duda, 1927: 142.

Specimens examined. [RYUKYUS] Okinawa P: 2 \&, Yona, Kunigami V, 25.iii.2000 (As.1060, 1068); 1 \&, Gogayama, Nakijin V, 17.iv.1996 (As.1059).

Distribution. China (Taiwan) (Duda, 1927) and Japan (Ryukyus: Fig. 5).

Remarks. This species is distinguished from congeners by the following characters: arista with long branches (Fig. 12a); face with white transverse band (Fig. 12a); gena dark brown (Fig. 12a); 2 pairs of dorsocentral setae present; scutum entirely dark brown; scutellum entirely yellow; katepisternum with dark marking.

\section{Asteia nigrigena sp.n.}

(Figs 2f, 3f, 5, 13a-c, 14a-c)

Asteia sp.; Tamaki, 1997: 148. (in part.)

\section{Description}

Male. Head (Fig. 13a) higher than long; anterior half of frons yellow brown, posterior half dark brown, entirely bare; orbital plate and ocellar triangle dark brown in ground colour, polished; anterior apex of interfrontal stripe slightly beyond anterior ocellus (Fig. 2f); face dark brown in ground colour, with white transverse band on ventral half; parafacial and gena dark brown; occiput and dorsal half of postgena dark brown; ventral half of postgena dark yellow. Head chaetotaxy: 1 orbital, 1 ocellar, 1 inner vertical, 1 outer vertical, 1 vibrissal, 2 subvibrissal, 1 genal and several postgenal setae all black; postocellar seta absent; minute setula present anterior to orbital seta. Scape and pedicel of antenna dark brown in ground colour; postpedicel yellow brown in ground colour, dorsal $1 / 3$ of postpedicel dark brown; arista black, with 3 dorsal and 2 ventral branches; pedicel with long seta dorsally; postpedicel covered with white setulae. Mouth parts yellow.

Thorax entirely yellow in ground colour, with dark brown markings; mesonotum entirely dark brown except yellow postalar wall, scutellum entirely yellow; propleural lobe and notopleuron dark brown; thoracic pleura yellow in ground colour, katepisternum and katepimeron with longitudinal dark brown markings. Thoracic chaetotaxy: $2 \mathrm{dc}, 1 \mathrm{pal}, 2 \mathrm{npl}, 2$ kepst and 1 sctl all black; 3 


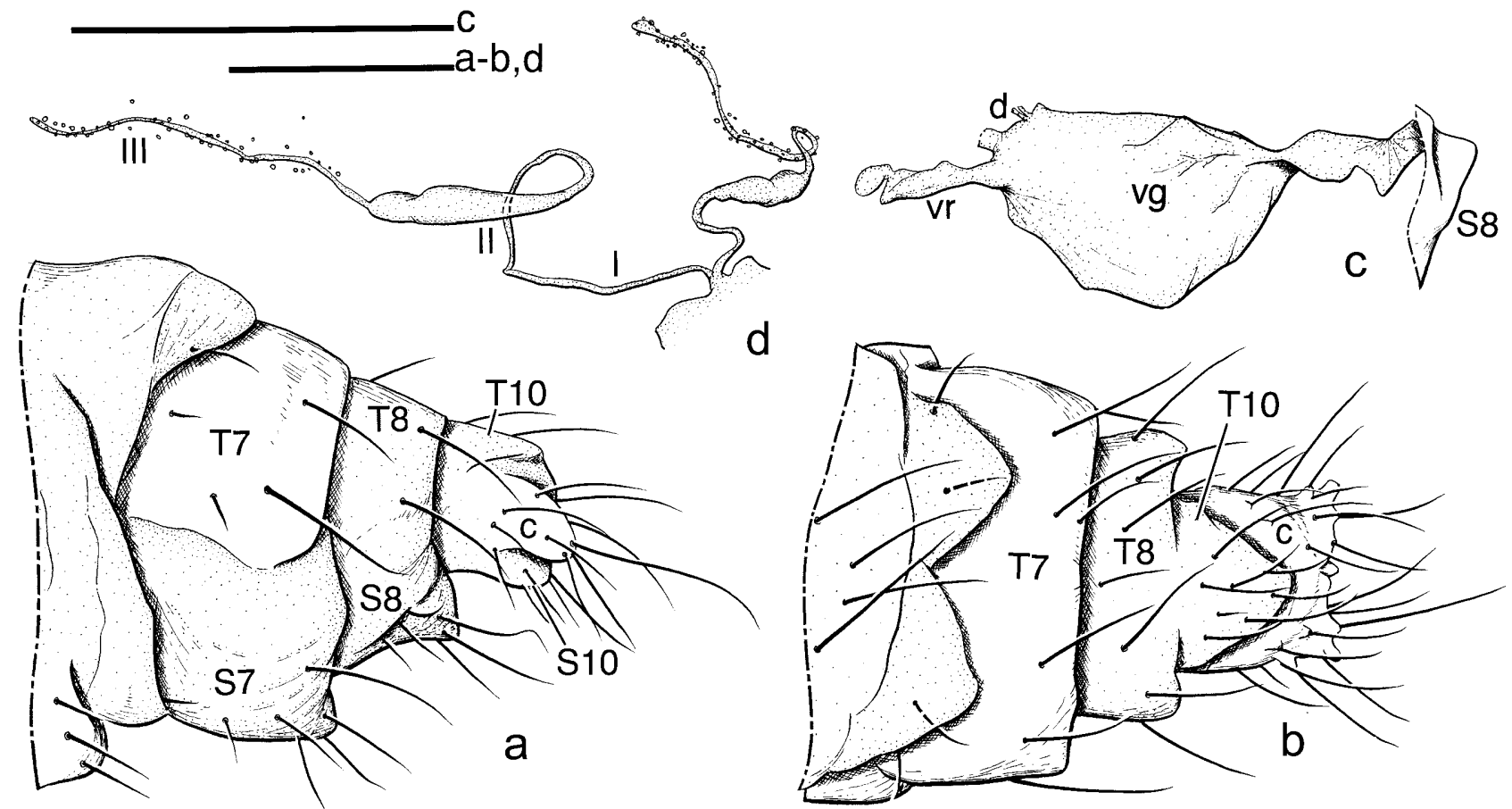

Fig. 10. Female (As. 1064) of Asteia longistylus sp. n. a - postabdomen in left lateral view; $\mathrm{b}$-postabdomen in dorsal view; $\mathrm{c}-$ genitalia in left lateral view; $d-$ spermathecae and spermathecal ducts. Scale bars: $a-b=0.10 \mathrm{~mm} ; \mathrm{c}=0.33 \mathrm{~mm} ; \mathrm{d}=0.05 \mathrm{~mm}$. Refer to the text for the abbreviations.

minute $d c$ present posterior to transverse suture; minute setula present anterior to sctl.
Wing (Fig. 3f) hyaline, 3 times longer than wide; veins pale brown; costal section between apices of $R_{1}$ and $R_{2+3}$ shorter than $\mathrm{R}-\mathrm{M}$ crossvein; apex of vein $\mathrm{CuA}_{1}$ close to

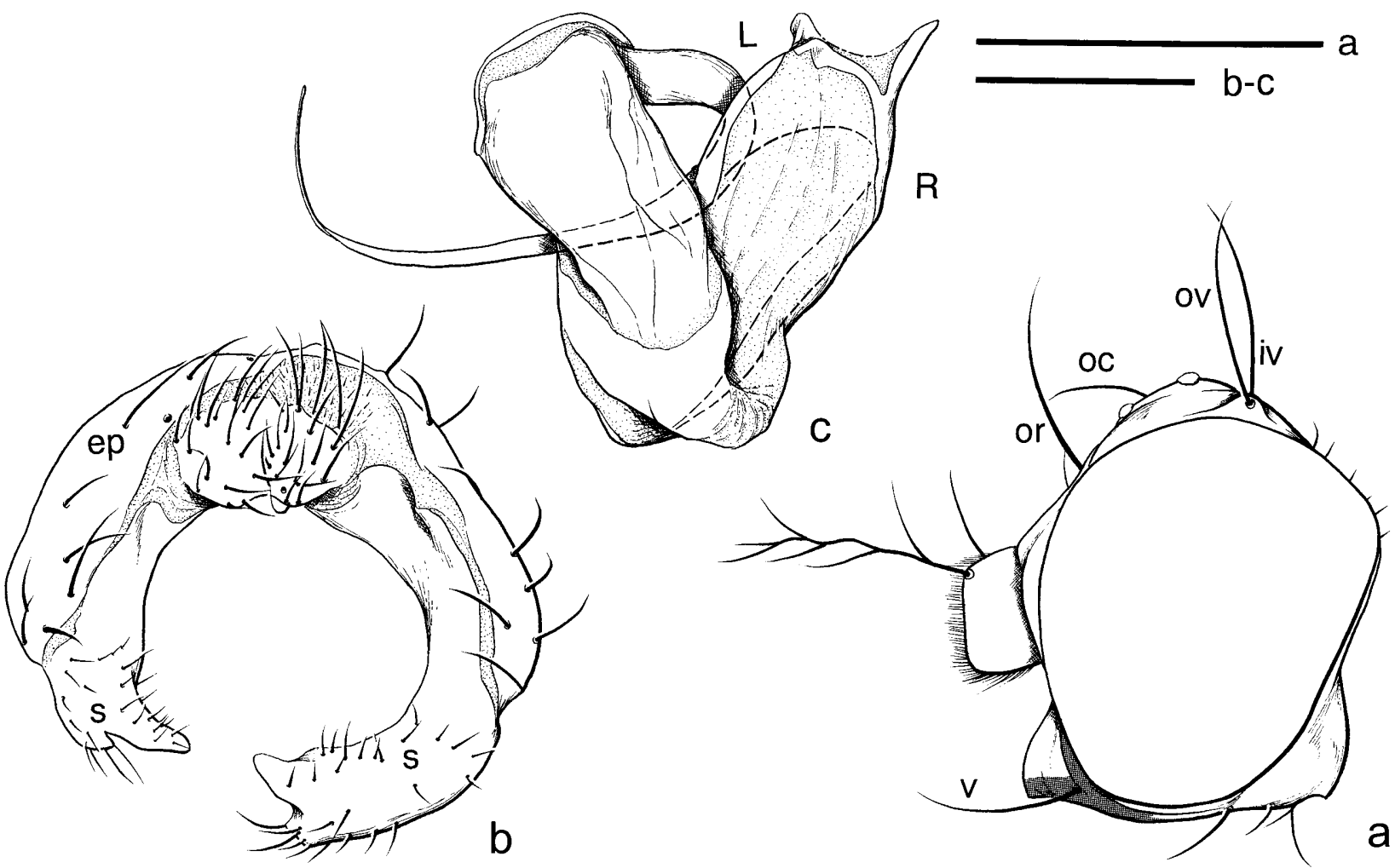

Fig. 11. Male (holotype) of Asteia lunaris sp. n. a - head in left lateral view; b - epandrial complex in caudal view; $\mathrm{c}$ - distiphallus on in left lateral view. Scale bars: $\mathrm{a}=0.33 \mathrm{~mm} ; \mathrm{b}-\mathrm{c}=0.10 \mathrm{~mm}$. Refer to the text for the abbreviations. 


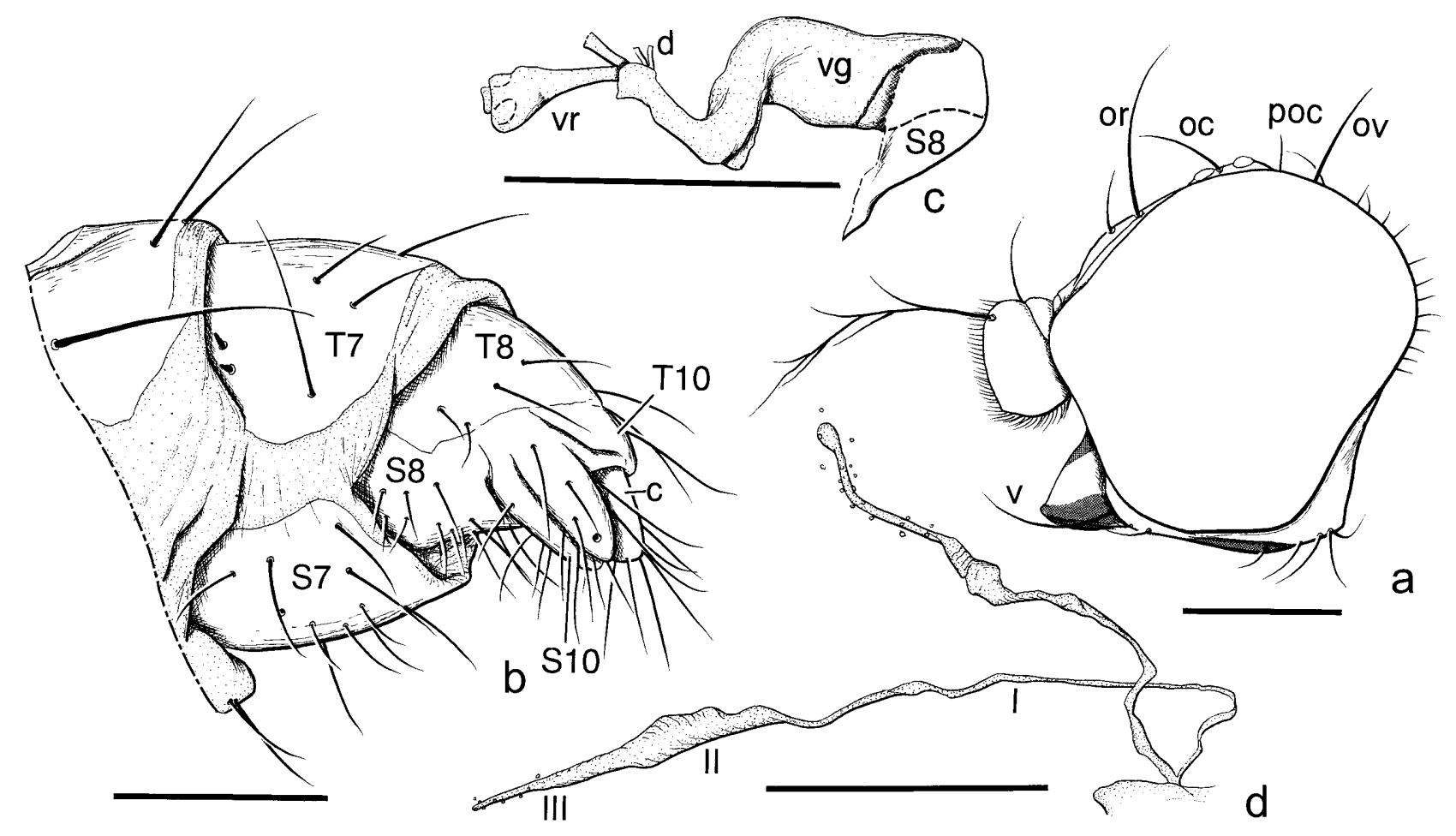

Fig. 12. Female (As. 1064) of Asteia megalophthalma Duda, 1927. a - head (As.1059) in left lateral view; b - postabdomen (As.1068) in left lateral view; $\mathrm{c}$ - genitalia (As.1059) in left lateral view; $\mathrm{d}$ - spermathecae and spermathecal ducts (As.1068). Scale bars: $\mathrm{a}-\mathrm{b}, \mathrm{d}=0.10 \mathrm{~mm}$; $\mathrm{c}=0.33 \mathrm{~mm}$. Refer to the text for the abbreviations.

posterior margin of wing but not reaching it. Halter yellow, knob dark brown.

Legs entirely yellow.

Abdomen yellow in ground colour, abdominal tergites slightly pale brown; T5 with broad transverse dark brown marking; abdominal sternites entirely yellow. Genitalia (Fig. 13b-c): epandrium (Fig. 13b-c: ep) short; surstylus (Fig. 13b-c: s) with blunt posterior process; hypandrium with postgonite (Fig. 13c: pog); basiphallus cylindrical, pointed posteriorly; distiphallus (Fig. 13c) coiled, consisting of basal tube laterally sclerotized, mesal complex tube and apical slender wire-like process.

Body length $1.9 \mathrm{~mm}$; wing length $2.1 \mathrm{~mm}$, width 0.7 $\mathrm{mm}$.

Female similar to male except postabdominal structures: T6-7 and S6-7 separate and broad plate-like; 3 short peg-like setae present on anterolateral margin of $\mathrm{T} 7$ (Fig. 14a); T8 trapezoid plate-like, as long as T7 (Fig. 14a); S8 triangular, as long as T8, shorter than S7 (Fig. 14a); T10 and S10 triangular; cercus as long as T10, right-angled triangular in dorsal view. Genitalia: vagina (Fig. 14b: vg) curved in S-shape in lateral view; ventral receptacle (Fig. 14b: vr) broadened and cup-like in middle, with appendix as long as other part of ventral receptacle. Two spermathecae present: spermathecal duct consisting of posteriorly narrowed (Fig. 14c: I) and anteriorly expanded sections (Fig. 14c: II); anterior half of expanded section spindle-like, shorter than narrowed section; spermatheca (Fig. 14c: III) covered with numerous intracellular canaliculi, as long as expanded section of spermathecal duct.

Type material. Holotype o : "Mt. Enkai / Yokohama City / Kanagawa Pref. / Honshu Japan / 15.viii.2002 / M.Sueyoshi leg.", "As.1074", lime green circle, "Holotype / Asteia / nigrigena / Sueyoshi" (red square label) (BLKU). Paratypes 8 o 10 †. [HONSHU] Saitama P: 2 क, Minowada, Moroyama T, 3.vi.1994 (As.2015-16); 1 o, same locality, 16.vi.1993 (As.2014). Kanagawa P: 1 \&, Segami, Yokohama C, 24.vii.1999 (As.2018), 6 क 6 \%, same data as holotype (As.1071-1073, 1075-1083); 1 \%, same locality, 19.ix.2000 (As.1058). Chiba P: 1 \&, Mt.Gunchari, Ichinomiya T, 28.viii.1999 (As.2019).

Etymology. The specific epithet refers to the dark coloured gena and postgena.

Distribution. Japan (Honshu: Fig. 5).

Remarks. This species is distinguished from congeners by the following characters: interfrontal stripe of male extended anteriorly to anterior ocellus (Fig. 13a); face with white transverse band (Fig. 13a); 2 pairs of dorsocentral setae present; scutellum entirely yellow; katepisternum with dark marking; abdominal tergite of male lacking dark markings except 5 th abdominal tergite with transverse dark marking. It is very similar to $A$. chinica in appearance but differs from it in wing veins $\mathrm{R}_{1}$ and $\mathrm{R}_{2+3}$ being very close, length between apices shorter than R-M crossvein (Fig. 3f), knob of halter dark brown, 1-4th abdominal tergites of male lacking dark markings, and 5 th abdominal tergite of male with unpaired transverse 


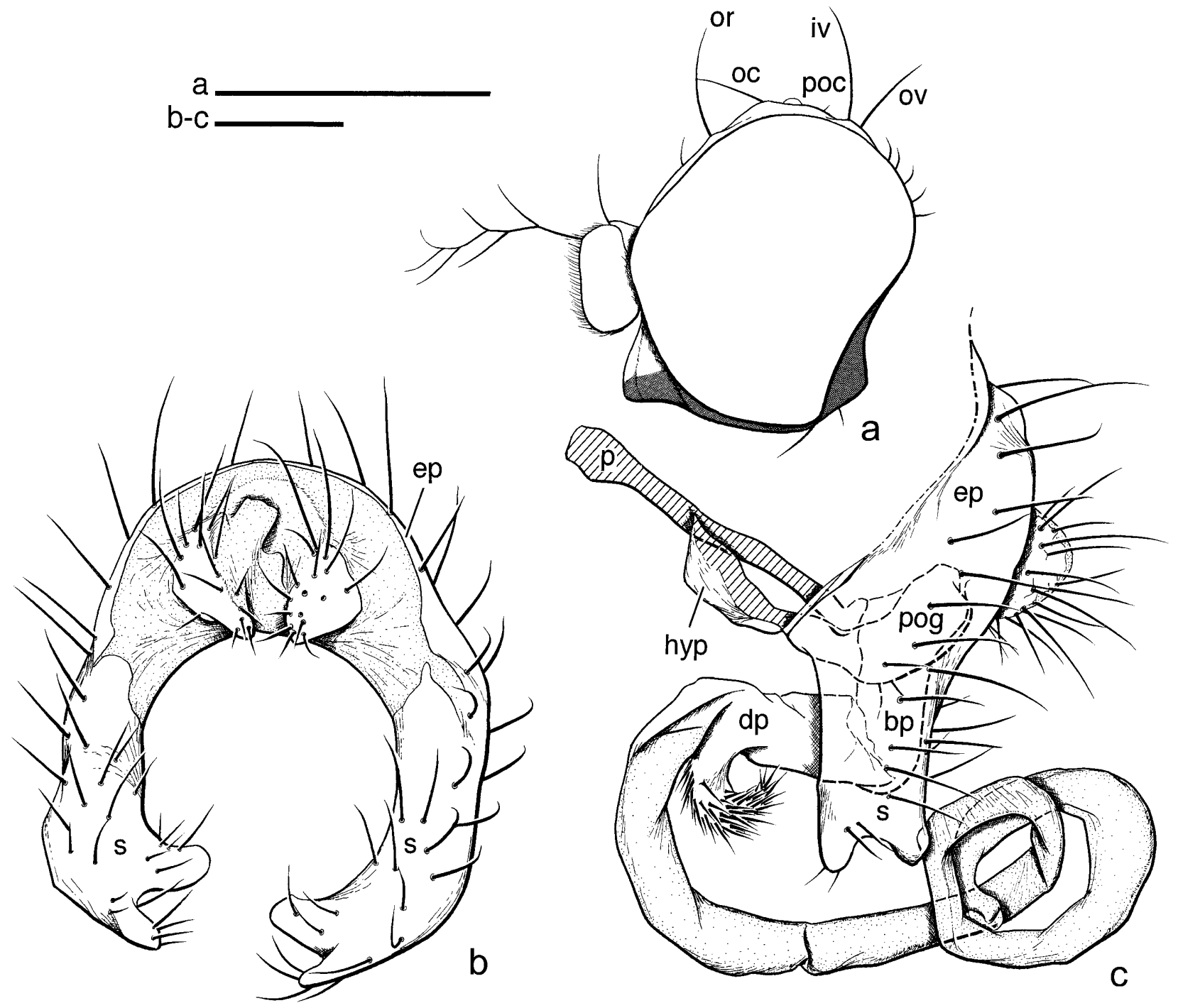

Fig. 13. Male (holotype) of Asteia nigrigena sp. n. a - head in left lateral view; b - epandrial complex in caudal view; $\mathrm{c}-$ genitalia in left lateral view. Scale bars: $a-b=0.25 \mathrm{~mm} ; \mathrm{c}=0.13 \mathrm{~mm}$. Refer to the text for the abbreviations.

dark marking. It also differs from $A$. longistylus and $A$. lunaris by postgena entirely dark brown (Fig. 13a).

Tamaki (1997) and Kubo (2000) reported an undetermined species of Asteia, respectively. I examined their specimens and found that some of them belong to this species.

\section{DISCUSSION}

More than 100 species of the Asteiidae have been described from all over the world since Meigen's (1830) description of $A$. amoena Meigen, 1830. Male genitalia of some species of this family have been described and illustrated briefly by authors. However, there are few reports comparing the male genitalia of species and the female genitalia, e.g. vagina and ventral receptacle have not been described, except the spermathecae.

In this study I examined eight species of Asteia, including $A$. amoena and $A$. concinna and found distinct differences in male and female genitalia of these species. Five of the species could be classified into two groups based on the morphology of the male distiphallus: the $A$. amoena and $A$. concinna groups. Asteia angustipennis, $A$. concinna and $A$. gemina belong to the latter group. Their male distiphallus in the $A$. concinna group consists of a pair of lateral sclerites elongated apically and bearing plate-like sclerites (Figs 1e-f, 6d-e, 8b: $\delta, \gamma$ ), and with a spiral apex (Figs 1e-f, 6d-e, 8b: $\beta$ ). Of the lateral sclerites of the distiphallus, the right lateral sclerite is directed anterodorsally and has a spine-like projection apically (Figs 1f, 6d-e: $\alpha$ ). The left lateral sclerite is directed anteroventrally and has a half-pipe plate-like sclerite (Figs 1e-f, 6d-e, 8b: $\delta$ ) under and supporting the apex of the distiphallus. In $A$. angustipennis and $A$. gemina, this sclerite bears a curtain-like sclerite (Figs 1e-f, 6d-e: $\gamma$ ). The apex of the distiphallus of the concinna group has a series of spiral folds (Figs 1e-f, 6d-e, $8 \mathrm{~b}: \beta 1-3$ ) as if it was twisted spirally. The apical half of these folds bear numerous spinose tubercles.

Asteia amoena and A. lunaris belong to the A. amoena group. Their male distiphallus consists of the basal tube 


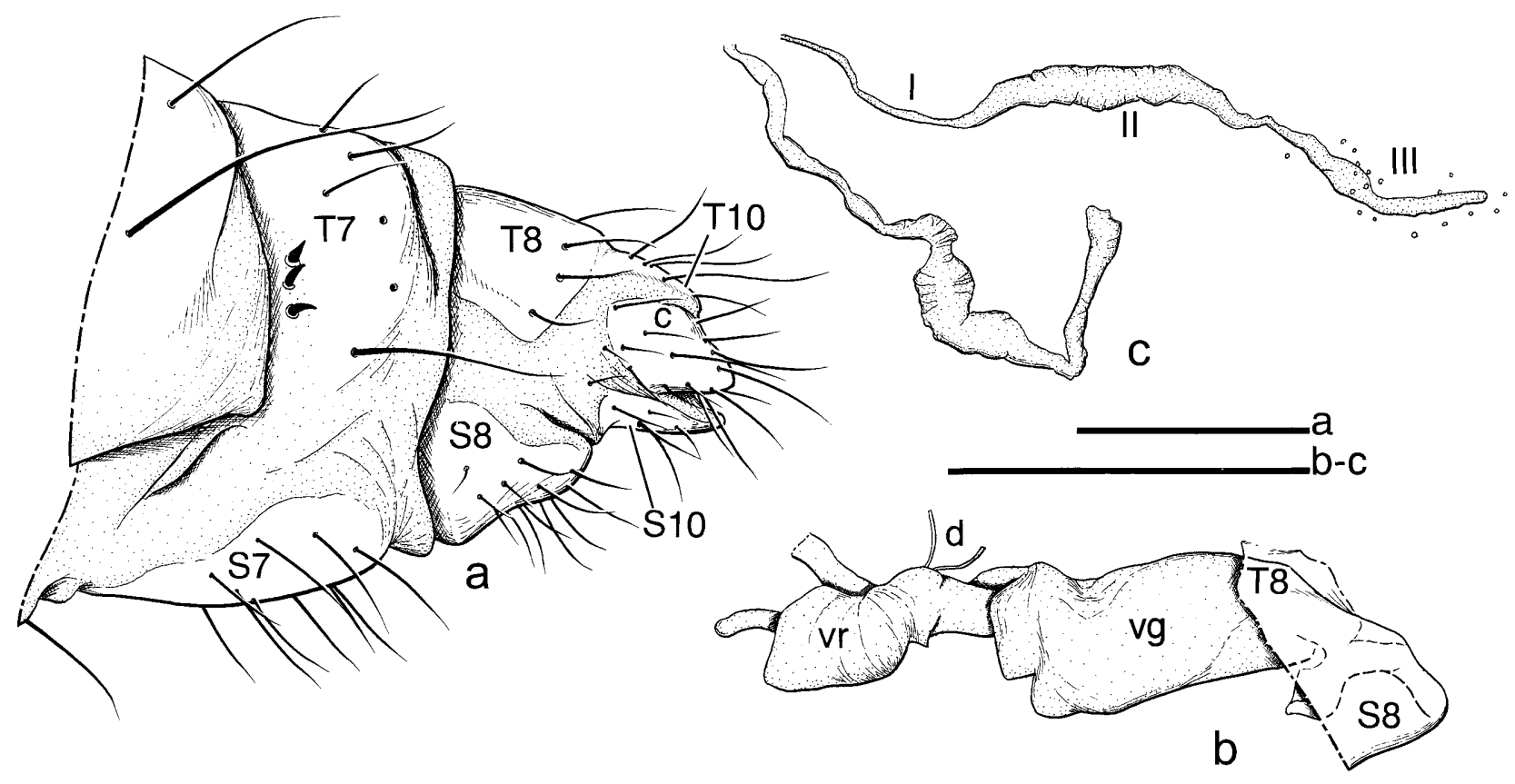

Fig. 14. Female (As. 2018) of Asteia nigrigena sp. n. a - postabdomen in left lateral view; b-genitalia in left lateral view; c-, spermathecae and spermathecal ducts. Scale bars: $a=0.20 \mathrm{~mm} ; b=0.25 \mathrm{~mm} ; \mathrm{c}=0.10 \mathrm{~mm}$. Refer to the text for the abbreviations.

with a pair of lateral sclerites as in the $A$. concinna group and the mesal tube contains a complex sclerite in front of the basal tube (Fig. 11c; Papp, 1998, Fig. 25.11). The left lateral sclerite (Fig. $11 \mathrm{c}$ : L) of this group is terminated abruptly and touches the anterior margin of the mesal tube. The right lateral sclerite (Fig. 11c: R) is tapered apically and becomes indistinct at the anterior margin of the mesal tube. The mesal tube of the distiphallus meets the basal part tube of the distiphallus at an acute angle, and bears a slender wire-like apical process in A. lunaris (Fig. $11 \mathrm{c})$, but terminates in a triangle short apex in $A$. amoena (Papp, 1998: Fig. 25.11). Asteia longistylus and A. nigrigena do not belong to either of the above groups. The distiphallus of $A$. longistylus is characterized by the absence of the sclerotized part as in the lateral sclerites of the $A$. amoena and the $A$. concinna groups (Fig. 9d). The distiphallus of $A$. nigrigena characteristically lacks the lateral sclerites basally and has a wire-like elongation longer than the remaining portion of the phallus and a short appendix on the basal portion of distal wire-like elongation (Fig. 13c). Males of $A$. megalophthalma are unknown.

Female genitalia consist of the vagina, ventral receptacle (Figs 4b-c, 7b-c, 8b-c, 10b-c, 12c, 14b: vg, vr), pair of accessory glands, and spermathecae (Figs 4d, 7d, 8e, $10 \mathrm{~d}, 12 \mathrm{~d}, 14 \mathrm{c})$. These structures are entirely membranous in the species examined and difficult to compare, but the following characters could be observed. In the female genitalia of the $A$. concinna group, the vagina has a ventral pocket (Figs $4 b-c, 7 b-c, 8 c-d: p$ ) in posterior $2 / 5$ and flattened stiff ventral floor (Figs 4c, 7c, 8d: vf). The apex of the ventral receptacle (Figs $4 b-c, 7 b-c, 8 c-d: v r$ ) is expanded and rounded. The expanded section of the spermathecal duct (Fig. 4d: II) is longer than two times the narrow section (Fig. 4d: I). The distal half of the expanded section is spindle-like. The spermatheca (Fig. 4d: III) is as long as the spindle part of the expanded section of the spermathecal duct. Although the morphological differences in the male distiphallus of $A$. amoena, A. longistylus, and $A$. nigrigena are distinct (Figs 9d, 13c; Fig. 25.11 in Papp, 1998), the female genitalia of these species and $A$. megalophthalma are very similar. The vagina (Figs 10c, 12c, 14b: vg) of these species is simpler than that of the $A$. concinna group and the flattened ventral floor and ventral pocket in the vagina are absent. The ventral receptacles (Figs 10c, 12c, 14b: vr) are pigmented along the apex. The spermathecal ducts also have a narrow section (Figs 10c, 12c, 14b: I) and an expanded section (Figs 10c, 12c, 14b: II) as in the $A$. concinna group. However, the expanded section does not have a spindle-like part and the narrow section is as long as or longer than the expanded section in these species. The spermatheca (Figs 10c, 12c, 14b: III) is approximately as long as the expanded section of the spermathecal duct in these species. The female of $A$. lunaris is unknown.

There is a marked difference in the morphology of male and female genitalia of species in the $A$. concinna group and the other five species. The right lateral sclerite has a pointed apex, the distiphallus a spirally twisted apex and spinose tubercles, the vagina a flattened ventral floor and ventral pocket in species of the $A$. concinna group. Although the position of the male distiphallus within the female vagina during copulation is unclear, the shapes of the distiphallus may affect the female vagina of this group in different ways than in other species when copulating.

The $A$. concinna group may be assigned to a new genus or subgenus based on the above morphological features. However, it is necessary to precisely compare the morphological features of the 70 species assigned to Asteia. These species must be classified into several monophyle- 
tic units, such as the $A$. concinna and $A$. amoena groups, and autapomorphic characters defining each group, such as the spirally twisted apex in the distiphallus of $A$. concinna group, recognized. The male distiphallus and female genitalia are useful and excellent characters for the classification of the species of Asteia.

It is worth noting, the similarities in the morphological and geographical distribution patterns of the species of the $A$. concinna group. Asteia gemina is very similar to $A$. concinna in external appearance and female genitalia but differ in the shape of the left lateral sclerite of the male distiphallus (Figs 6d, 8b). The former species distinctly differs from $A$. angustipennis in body colour and markings, but has very similar male and female genitalia (Figs 1b-f, 6b-e). Preliminary distribution ranges for these species were compiled in this study. Asteia concinna was originally known only from Europe, but Yang \& Zhang (1996) recorded it from China. Asteia angustipennis and A. gemina are known only from the Asian part of Russia and Japan. In Hokkaido, Japan, they are sympatrically distributed geographically and temporally. Asteia concinna and A. gemina are distributed allopatrically as far as is known. At the present, the phylogenetic relationships between these three species of the $A$. concinna group and other species of Asteia are unresolved. However, morphological similarities between these species suggest that they are closely related and their morphological characters reflect reproductive isolation. The male distiphallus in $A$. concinna and $A$. gemina differ greatly in shape (Figs 6d-e, $8 \mathrm{~b}$ ), but morphological features of the female vagina are not distinctly different in these two species (Figs $7 \mathrm{~b}-\mathrm{c}, 8 \mathrm{c}-\mathrm{d}$ ). Therefore, $A$. concinna and $A$. gemina may be isolated by differences in male genitalia and their geographical distributions, with the latter more important than the former. Asteia angustipennis and $A$. gemina differ in body markings and it is possible that these species may be more isolated from one another than $A$. concinna and $A$. gemina.

\section{KEY TO JAPANESE SPECIES OF ASTEIIDAE}

1 Two pairs of orbital setae present; scutum with 1 dorsocentral seta; anterior scutellar seta as long as posterior seta; wing with $\mathrm{dM}-\mathrm{Cu}$ crossvein and alula distinct, with long plumosity ................ Astiosoma okinawae

- One strong pair of orbital setae present (Figs 1a, 6a, 9a, 11a, 12a, 13a); scutum with 2 dorsocentral setae; scutellum with 1 pair of scutellar setae; wing without $\mathrm{dM}-\mathrm{Cu}$ crossvein and alula ( Fig. 3a-f) ..................... 2

2 Scutellum with semicircular dark brown marking on disc; knob of halter yellow, concolourous with stem, or slightly darker than stem $\ldots \ldots \ldots \ldots \ldots \ldots \ldots \ldots . \ldots \ldots$

- Scutellum entirely yellow, without dark markings except for narrow dark brown band on anterior margin; knob of halter dark brown, distinctly darker than yellow stem . . . . . . 4

3 Face yellow in ground colour, with pair of dark brown markings on lateroventral side (Fig. 6a); scutum dark brown $\ldots \ldots \ldots \ldots \ldots \ldots \ldots \ldots \ldots$ Asteia gemina

- Face dark brown in ground colour, with white transverse band on ventral half (Fig. 1a); scutum black

......................... Asteia angustipennis

4 Gena yellow (Figs 9a, 12a). . . . . . . . . . . . 5
- Gena dark brown (Figs 11a, 13a). . ............ 6

5 Katepisternum without dark markings .. Asteia longistylus Katepisternum with dark markings $\ldots \ldots \ldots \ldots \ldots$

Asteia megalophthalma

6 Postgena yellow in contrast to dark brown gena (Fig. 11a

............................ Asteia lunaris

Postgena dark brown, concolourous with gena (Fig. 13a) ..

Asteia nigrigena

ACKNOWLEDGEMENTS. I thank L. Papp (Zoological Department, Hungarian Natural History Museum, Budapest) and B.J. Sinclair (Zoologisches Forschungsinstitut und Museum Alexander Koenig, Bonn) for reviewing of an early draft of this paper and for critical comments. I thank B. Merz (Muséum d'Histoire Naturèlle, Genève), H. Nakayama (BLKU) and N. Tamaki (Saitama P) for making specimens available for this study.

\section{REFERENCES}

Carles-Tolrá M. 1998: Description of a new Phlebosotera species from Spain (Diptera: Asteiidae). Studia Dipter. 5: 55-57.

Cumming J.M., SinClair B.J. \& WOOD D.M. 1995: Homology and phylogenetic implications of male genitalia in Diptera Eremoneura. Entomol. Scand. 26: 121-151.

DudA O. 1927: Revision der altweltlichen Asteiidae (Dipt.). Dt. Entomol. Z. 11: 113-147.

Duda O. 1934: 58b. Asteiidae. In: Lindner E. (ed.): Die Fliegen der Palearktischen Region 6. E. Schweizerbart'sche Verlagsbuchhandlung, Stuttgart, $14 \mathrm{pp}$.

Ferrar P. 1987: A Guide to the Breeding Habits and Immature Stages of Diptera Cyclorrhapha. Entomonograph 8. (Pt.1 \& Pt.2), E.J. Brill/Scandinavian Science Press, LeidenCopenhagen, $907 \mathrm{pp}$.

GrifFItHs G.C.D. 1981: Book review of "Manual of Nearctic Diptera. Volume 1. J.F. McAlpine, B.V. Peterson, G.E. Shewell, H.J. Teskey, J.R. Vockeroth, D.M. Wood (Editors)". Entomol. Soc. Can., Bull. 13: 49-55.

Kuво K. 2000: The insects of Enkai Mountain Region, Diptera. Kanagawa-Chuho, Odawara 130: 347-395. [in Japanese]

MCAlPINE J.F. 1981: 2. Morphology and terminology - adults. In: McAlpine J.F., Peterson B.V., Shewell G.E., Teskey H.J., Vockeroth J.R. \& Wood D.M. (eds): Manual of Nearctic Diptera, Vol. 1. Research Branch, Agriculture Canada Monograph 27. Can. Govern.t Publ. Centre Supply and Serv. Can., Hull, pp. 9-63.

MeIGeN J.W. 1830: Systematische Beschreibung der bekannten europäischen zweiflügeligen Insekten Vol. 6., Hamm, iv +401 pp.

PAPP L. 1972: Asteiidae (Diptera) from Mongolia. Acta Zool. Acad. Sci. Hung. 18: 93-100.

PAPP L. 1974: Some Diastatidae, Camillidae, Aulacigastridae and Asteiidae (Diptera) from Asia. Acta Zool. Acad. Sci. Hung. 20: 117-181.

PAPP L. 1984: Family Asteiidae. In: Soós A. \& Papp L. (eds): Catalogue of Palaearctic Diptera, Vol. 10. Akadémiai Kiadó, Budapest \& Elsevier Sci. Publ., Amsterdam, pp. 63-66.

PAPP L. 1992: Immature stages of Leiomyza dudai Sabrosky, 1956 (Diptera: Asteiidae: Sigaloessinae). Acta Zool. Hung. 38: $313-320$.

PAPP L. 1998: Family Asteiidae. In: Papp L. \& Darvas B. (eds): Contributions to a Manual of Palaearctic Diptera, Vol. 3 (Higher Brachycera). Science Herald, Budapest, pp. 295-303.

SABrosky C.W. 1956: Additions to the knowledge of Old World Asteiidae (Diptera). Rev. Fr. Entomol. 23: 216-243.

SABrosky C.W. 1977: Family Asteiidae. In: Hardy D.E. \& Delfinado M.D. (eds): A Catalog of the Diptera of the Ori- 
ental Region, Volume III, Suborder Cyclorrhapha (excluding Division Aschiza). The University Press of Hawaii, Honolulu, pp. 232-233.

SABrosky C.W. 1987: 78. Asteiidae. In: McAlpine J.F., Peterson B.V., Shewell G.E., Teskey H.J., Vockeroth J.R. \& Wood D.M. (eds): Manual of Nearctic Diptera, Vol. 2. Research Branch, Agriculture Canada Monograph 27. Can. Com. Group-Publ., Ottawa, pp. 899-902.

StUCKenBerg B.R. 1999: Antennal evolution in the Brachycera (Diptera), with a reassessment of terminology relating to the flagellum. Studia Dipter. 6: 33-48.
Tamaki N. 1997: Diptera of Saitama Prefecture. In: Usui T. (ed.): Insects of Saitama, Japan, Vol. 2 (Diptera). Saitama Kontyu Danwakai, Omiya, 405 pp. [in Japanese]

THEODoR O. 1976: On the Structure of the Spermatheca and Aedeagus in the Asilidae and their Importance in the Systematics of the Family. The Israel Acad. Sci. Human., Jerusalem, $175 \mathrm{pp}$.

Yang C. \& Zhang X. 1996: Asteiidae. In: Wang X. \& Chienming C. (eds): Flies of China, Vol. 1. Liaoning Sci. Technol. Press, Shenyang, pp. 489-500.

Received November 18, 2002; revised February 24, 2003; accepted April 14, 2003 